\title{
GREENER HOUSEHOLDS? THE EFFECTIVENESS OF SMART METERS IN REDUCING ENERGY CONSUMPTION LEVELS IN THE DACH REGION
}

\author{
M. BAUER ${ }^{1}$, A. HOELTL ${ }^{2} \&$ R. BRANDTWEINER ${ }^{1}$ \\ ${ }^{1}$ Institute of Information Management \& Control, Vienna University of Economics and Business, Austria. \\ ${ }^{2}$ Department for Management and Economics, Danube University Krems, Austria.
}

\begin{abstract}
With public opinion shifting to a believe in climate change in the early 2000s the interest in energy efficiency has been increasing. EU Directives set the goal of deploying smart meters if cost efficient for providing more detailed energy consumption. The main goal is to better inform consumers and to give individual households the power to change possibly energy wasting behaviours. This paper evaluates through a literature review the effectiveness of intelligent electricity metering systems with a focus on the DACH region, the provision of different types of feedback and its persistence. It can be concluded that energy feedback enabled by smart meters can lead to savings in the range of $0 \%$ to $4.5 \%$ in this region. If feedback is provided continuously savings persist. However, several aspects have to be considered to ensure effectiveness of smart meter deployment.
\end{abstract}

Keywords: DACH region, energy feedback, energy savings, households, intelligent metering system, smart meters

\section{INTRODUCTION}

In 2009 the European Parliament published the Directive concerning common rules for the internal market in electricity stating the aim of deploying intelligent meter systems. The goal is to employ these smart meters at $80 \%$ of all households by 2020 if there is a positive national economic assessment. The main reason for this is the need of modernising the electricity infrastructure in order to reach the goal of reducing carbon dioxide emissions and ongoing changes in the structure of energy markets such as consumers turning into producers, thus a decentralisation of energy production. Smart meters shall deliver detailed consumption readings. By giving real-time feedback and historical or normative feedback to consumers the goal is to induce households to change their consumption behaviour towards saving energy. Smart meters allow different types of feedback, such as direct feedback from the utility provider giving comparisons to prior year's consumption level or indirect feedback through electricity bills. In this paper the effectiveness of smart meters to reduce energy consumption per household is analysed and compared based on published empirical work with a focus on the DACH region.

The European Union aims to transform present passive energy grids to active, intelligent networks. One essential part of so-called smart grids is smart meters. In contrast to traditional energy consumption meters these intelligent meter systems offer a wide variety of possibilities, such as delivering meter readings to utility companies electronically and providing households with monthly, weekly or even daily feedback on their energy usage level. On the one hand industrial companies can be urged to lower their energy consumption levels by changing or adapting environmental laws and regulations. On the other hand households might be induced to save energy, when direct or indirect feedback is given to them on a regular basis. The process of giving feedback can be simplified through smart meters, but low energy prices might counteract a shift to a consistent decrease in energy consumption and corresponding incentives. 
The aim of this paper is to investigate the effectiveness of different types of feedback made possible by the deployment of smart meters in households of the DACH region, to discuss factors contributing to a more energy saving behaviour of households and to discuss the role of information systems in reducing energy consumption levels.

\section{WHY SMART METERS}

The most important human emitted GHG is carbon dioxide with a rise in annual global emissions of $80 \%$ between 1970 and 2004 [1]. Potential impacts of the increase in global average temperatures include among others a higher risk of scarcity of water, an increase in the risk of species extinction, higher wildfire risk, decreases in the productivity of cereals and higher food and storm damages. If the current trend of rising emissions is not stopped, it is estimated that by the year 2035 global average temperatures will increase by more than $2^{\circ} \mathrm{C}$ [2].

According to the Stern review prevention of climate change is not possible as it is already underway, but consequences may be limited by actions taken now. The costs of effective actions to reduce GHG emissions are estimated to be low (1\% of global GDP), when compared to estimates of costs through damages (lower bound at around 5\% of global GDP) [2]. Mitigation of climate change includes several key components of GHG reduction policies and technology options. One decisive field of action is the supply and the infrastructure of energy, another is the field of energy use. Measures can be set to reduce usage for buildings and residences through improved insulation. For appliances and lighting a decrease in energy consumption can be achieved through energy labelling and the promotion of energy efficiency and energy services.

\subsection{Definition of smart meters}

Traditional and conventional electro-mechanical meters have not substantially changed over the last 50 years and have some deficiencies: aggregated meter readings have to be taken on site resulting in high personnel and administrative costs. In Austria, meters are read only once a year. Readings are aggregated values, thus it is not possible to impose time-variant tariffs [3].

A smart meter is a usage-reporting device and can potentially be used for different fields of measurement, such as for gas, water or electricity. In this paper we focus on smart meters collecting information on energy consumption. There are currently several types of meters offered on the market, but only the latter is considered to be a smart meter: Traditional mechanical electricity meters may simply be upgraded for remote readout, allowing accurate billing based on consumption data, instead of estimates. These devices can be categorised as Automatic Meter Reading (AMR) meters. Advanced Meter Management (AMM) or Advanced Metering Infrastructure (AMI) refers to the entire system of meters and associated communications. AMI meters allow two-way communication. Utility companies may limit or cut off energy supply or send information on price and tariff changes directly to households. Additionally, AMI meters ease the process of changing suppliers and help to detect fraud as readings can be taken remotely.

Furthermore, smart meters are a necessary component for enabling distributed generation as energy from solar panels or wind turbines can be measured accurately [3]. Additionally, smart meters may enable communication with other in-house devices such as for example heating or dishwasher. An overview of possible outcomes and functionalities of different smart metering stages is given in Table 1. Common literature agrees on the following configurations necessary for the definition of a fully smart meter [4]: Devices must be able to 
Table 1: Potential smart metering outcomes from a consumer standpoint [4].

\begin{tabular}{|c|c|c|c|c|}
\hline & $\begin{array}{l}\text { Customer } \\
\text { display }\end{array}$ & $\begin{array}{l}\text { Advanced } \\
\text { metering/AMR }\end{array}$ & $\begin{array}{l}\text { Smart metering/ } \\
\text { AMM (with AMI) }\end{array}$ & $\begin{array}{l}\text { Smart } \\
\text { grid }\end{array}$ \\
\hline $\begin{array}{l}\text { An end to estimated bills; no } \\
\text { need to wait in for a meter } \\
\text { reader to call }\end{array}$ & & $\times$ & $\times$ & $\times$ \\
\hline $\begin{array}{l}\text { Real-time and/or historic and } \\
\text { comparative consumption } \\
\text { feedback to the customer }\end{array}$ & $\times$ & Possible & Possible & Possible \\
\hline $\begin{array}{l}\text { Detailed consumption } \\
\text { feedback to the utility }\end{array}$ & & $\times$ & $x$ & $\times$ \\
\hline Fraud reduction & & $\times$ & $x$ & $x$ \\
\hline $\begin{array}{l}\text { Remote connection/ } \\
\text { disconnection }\end{array}$ & & & $x$ & $x$ \\
\hline Remote tariff switching & & & $x$ & $x$ \\
\hline Easier supplier switching & & & $x$ & $x$ \\
\hline Integration of microgeneration & & Possible & $x$ & $x$ \\
\hline $\begin{array}{l}\text { Remote control of appliances } \\
\text { for load management }\end{array}$ & & & Possible & $\times$ \\
\hline $\begin{array}{l}\text { Connections with home } \\
\text { security systems, etc. }\end{array}$ & Possible & Possible & Possible & Possible \\
\hline
\end{tabular}

Note: This is schematic only.

AMM, automated meter management; AMR, automated meter reading; AMI, advanced metering infrastructure.

measure and store consumption data at specified intervals and allow two-way communication. These meters gather and store consumption data at high-frequency rates and allow communication electronically from consumer to supplier and vice versa. Readings can be recorded at near-real time, but most commonly at 15-minute up to 1-hour intervals. Due to the possibility of measuring and having access to exact consumption data, utility companies may offer time-variant tariffs, i.e. higher prices at times of peak demand. Smart meters alone do not automatically urge households to conserve or consume less energy. Consumption displays or other in-home displays giving real-time, historical or normative feedback might help households to save energy and understand the effects of taken action.

\subsection{European smart meter legislature}

In 2006 Directive 2006/32/EC of the European Parliament and of the Council was declared with a focus on the promotion of energy end-use efficiency. It stated that all parties selling electricity must supply information to final customers for developing and implementing programmes for improving energy efficiency. Furthermore, "Member States must also ensure that end-users are provided with competitively priced individual metering and informative billing that shows their actual energy consumption. [...] Individual meters must be installed at a competitive price wherever economically and technically feasible." [5] 
In 2009 the European Parliament declared Directive 2009/72/EC concerning common rules for the internal market in electricity. It urges member states to have intelligent metering systems implemented if an economic assessment of the deployment thereof delivers a positive result meaning that total revenues exceed total anticipated costs. By 2020 the aim is to equip $80 \%$ of consumers with intelligent metering systems. The result should be that consumers "are properly informed of actual electricity consumption and costs frequently enough to enable them to regulate their own electricity consumption." [6]

In 2012 the Council of European Union amended Directive 2009/125/EC and repealed Directive 2006/32/EC. Energy Efficiency (Directive 2012/27/EU) states: "Such a competitively priced individual meter shall always be provided when: (a) an existing meter is replaced, unless this is technically impossible or not cost-effective in relation to the estimated potential savings in the long term; (b) a new connection is made in a new building or a building undergoes major renovations..." [7] Billing information must be accurate and based on actual consumption. Additionally, final customers shall have access to complementary information on historical consumption, including historical cumulative data.

\subsection{Energy Feedback}

The difficulty of curbing electricity consumption lies in the way electricity is consumed. Electricity is different to typical consumer goods, such as for example groceries: it is not visible and it is not consumed directly, but indirectly by being at home, taking a shower, watching television or reading a book [8].

Households then may collect prior bills or other additional information such as weather data in order to find out if the most recent bill was higher, lower or equal to prior demand. In case of any unexpected deviations the customer may put these in relation to any household activities, such as new appliances or more or less residents. In essence, the customer does not receive directly any information, which could potentially help to find out if energy conserving actions have had any effect. One possibility to induce households to curb electricity consumption is to provide more detailed feedback on related costs, related effects and problems (i.e. climate change) and on consumption itself. Underlying basis of this assumption is that providing more feedback on households' consumption raises awareness about for example high energy costs or a high environmental impact through carbon emissions.

Interpretations on and reactions to more or improved feedback may vary from household to household caused by different histories and social practices [9]. Fischer [8] relates to an integrated model and describes the process of how new norms might play a role in the decision making procedure of consumers. Electricity consumers must firstly become aware of the presence of a problem, secondly of the relevance of the own behaviour and thirdly of the possibility of changing the behaviour or outcome. She highlights the importance of presenting information and explains how different types of feedback may influence the behaviour of different types of consumers when using electricity.

Froehlich [10] provided a framework to shape effective feedback designs. It includes the following dimensions among ten in total with recommendations, which highlight important aspects: More frequent feedback allows improved understanding of the link between action and effect. There are different measurement units possible for energy feedback such as electricity consumption (in $\mathrm{kWh}$ ), costs (in Euro) or environmental impacts. Chosen measurement units must be comprehensible for individual households. Granularity in terms of time, space, 
source or source category. Users should have the possibility of choosing when, where, with which type of presentation and on which device they receive feedback. Also, feedback shall be accessible at all times to raise awareness and methods for comparative feedback increase the effectiveness and spur motivation. A wide range of factors including age, cost of energy, home ownership, income level and family size may have an impact on the effectiveness of feedback delivered.

\section{ENERGY MARKET AND SMART METERS}

Quantitative and qualitative studies deliver similar results on energy savings of $0 \%$ to $15 \%$ [4] due to the application of smart meters, using different feedback carriers and means of presentation including improved billing, in-house displays and website platforms. This section focuses on the energy markets of Austria, Germany and Switzerland and compares smart meter roll-out strategies and the status of the implementation.

\subsection{Austria}

Full liberalisation of the Austrian electricity market was undertaken in 2001. In 2014, 28\% of total electricity consumed was used in Austrian households (Statistik Austria, 2014). Participants in the grid, consumer or producer, enter a contract separately with the operator of the grid and with the supplier or trader. Meter readings from smaller consumers with annual consumption levels below $50 \mathrm{~kW}$ are taken once per year. Standardised load profiles are used for market participants which do not provide high-frequent (15-minute interval) readings. System operators are responsible for all meter-specific issues. These include installation, maintenance, removal of meters, as well as taking meter readings and submitting meter information to all relevant parties [11].

Based on the European Directive 2009/72/EG the Austrian government adopted a policy stating that all network operators are obliged to deploy intelligent metering systems at $70 \%$ of all metering points by 2017 and at $95 \%$ of all metering points within the bounds of technical feasibility by 2019. According to Austrian electricity regulator E-Control meters shall meet among others the following minimum functional requirements: two-way communication, metering of consumption data at 15 minute intervals, store data in the meter device and communication with other devices present in the customer facility. E-Control [11] estimates a roll-out of around 10\% or 590,000 smart meters in Austria by the end of 2016.

\subsection{Germany}

In 2016 the German Senate passed a law for nationwide deployment of smart meters (Digitisation of the Energy Turnaround Act). By this, Germany is adapting EU Directives 2009/72/EG and 2009/73/EG into German national law and the process of implementing smart meters is eased. Requirements for the design of smart meters and data transmission are set by this law.

Roll-out of intelligent metering systems will start in 2017 and will progress in roll-out phases for different types of consumers. With 2017 households and companies with an annual electricity consumption of more than 10,000 kWh have to install smart meters. By 2032 all conventional meters of consumers with annual consumption of more than $6,000 \mathrm{kWh}$ will be exchanged with smart meters [12]. The Meter Operator is responsible for all smart meter related issues, including the implementation, operation and maintenance. Energy supply grid 
operators are by law Meter Operators, but they may assign and transfer all services to third party service providers.

\subsection{Switzerland}

In Switzerland attempts to fully liberalise the energy market have been underway for several years. In 2007 Swiss parliament passed the Electricity Supply Act, which took effect in 2009 [13]. The Act stipulates that customers may freely choose their supplier. Since 2013 Swissgrid is responsible for operation, maintenance, renewal and expansion of the entire Swiss transmission grid and for guaranteeing access to it for all parties.

As preparation for a long-term energy policy a Smart Meter Impact Assessment was conducted and delivered a positive cost-benefit ratio in 2012 [14]. In the same year the Swiss Federal Office of Energy published the first set of measures, which aims to increase energy efficiency and to reduce the average electricity consumption per person compared to the level of the year 2000 by $3 \%$ by 2020 and by $13 \%$ by 2035 [15]. In Switzerland there are contrarily to the European Union neither political objectives nor pressure from customers for a smart meter roll-out. Nevertheless, some utility companies have undertaken projects to assess the effectiveness of smart meters.

\section{FEEDBACK MADE POSSIBLE BY SMART METERING DEVICES}

For receiving feedback, intelligent metering systems are not absolutely necessary, but as these systems may provide accurate consumption data, feedback can be given more frequently and in more detail. Motivated households may take meter readings at conventional electricity consumption meters day by day. Difficult access and time spent for this type of self generated feedback might not induce many households to map their readings and conserve energy.

Feedback on energy consumption is possible directly or indirectly. A large-scale experiment in Northern Ireland [16] with keypad meters shows savings in electricity consumption of $15 \%$ to $20 \%$. Keypad meters provide consumption information and costs on an interactive display and customers may add credit to their card for example online. However, it is unclear whether these savings come from a more economical behaviour of households in everyday routines or the purchase of new, more efficient home appliances for instance.

A qualitative field study examining the acceptance and usability of three different smart energy monitors (energy displays) was conducted in Eastern England involving in total 275 households over the period of one year (2008-2009) [9]. According to this study, monitors did not directly change awareness, but rather prompted the consumers to respond to high consumption levels for instance. Based on the availability of energy usage information some households made considered decisions concerning daily activities and paid special attention to energy efficiency and energy labels when purchasing new house appliances. However, effects on behaviour by the monitor did not change significantly compared to conclusions made from interviews one year prior.

Not only hardware solutions have been developed, but also software applications, which are web portals for online historical and normative comparisons. Visualised data or other notifications can be sent to customers' mobile phones or personal computers and access to more information than energy consumption is possible: Usage can be compared with friends or similar households and more efficient appliances may be searched for. In a living lab study 
of Schwartz [17] electricity usage decreased by $7.8 \%$ compared to consumption levels before deployment of the feedback system.

The raised popularity and everyday usage of mobile phones makes it possible to give easy, accessible feedback independent from place or time on these devices through customised applications. Users did not perceive social comparisons and the setting of saving targets as important. Probably interactivity of feedback is necessary for inducing households to save energy and to keep users interested in the topic.

Disaggregated feedback refers to information on energy consumption of individual appliances, such as refrigerators, personal computers or air conditioners. Knowledge of the consumption of individual appliances enables easier experimenting and finding out which devices use how much energy.

Indirect feedback is feedback which requires processing of data before reaching the customer. Information about energy consumption is indirectly delivered through for example electricity bills. Informative billing is not dependent on intelligent metering systems, but smart meters may provide cost savings [18]. Based on gained data and interviews with 1,286 participants the authors are sure that there is a link between an increase in feedback, increase in awareness or knowledge, changes in behaviour and a decrease in energy consumption.

A meta review analysed the persistence of savings of 57 studies and shows a median study duration of 5 months with higher mean energy savings in shorter studies (lasting for 6 months or less) of $10.1 \%$ compared to $7.7 \%$ in longer studies [19].

\section{DISCUSSION AND FUTURE RESEARCH}

Findings have shown that the implementation of smart meters is effective under the condition of delivering feedback gained through energy consumption data. Implementing smart meters without giving feedback to end-consumers may provide other useful purposes for utility companies. But, households will not be able to gain deeper knowledge and will not change potentially energy wasting behaviours.

Energy feedback in various forms helps to induce households to curb energy consumption in the range of $0 \%$ to $4.5 \%$ [20] for Austria and slightly higher savings in Germany and Switzerland. Results of pilot projects in Germany, Austria and Switzerland show similar results in the effectiveness of smart meters, while roll-out strategies and legislations are diverging. At the same time, smart meters are not the only basis for providing energy feedback. Disaggregated feedback may also be provided by using Non Intrusive Load Monitoring techniques which break down aggregated total energy consumption of households to individual appliances. Furthermore, the effectiveness or success of energy feedback provided on the basis of implemented intelligent metering systems highly depends on the acceptance and participation of consumers. Qualitative research has shown that the social context plays an important role whether households are willing to change behaviour and save energy. Roll-out of smart meters will still take several years until fully completed. In the meantime measures such as the provision of more frequent bills enable end-consumers to identify energy wasting routines and appliances. Olmos [21] similarly urge to provide advanced indirect feedback in the short term.

Energy feedback makes energy visible, comparable and may allow competition with e.g. neighbours. It also shows households that changes in behaviour can lead to actual savings in costs or reduce one's environmental impact. Effective feedback is always present, can be accessed in several ways, allows focusing on different levels of granularity such as appliance 
specific feedback and is easily understandable to end consumers. Energy monitors presenting real-time energy consumption may not be sufficient for ensuring effectiveness but savings may be increased when feedback is combined with tools for motivation and specific energy conserving suggestions and hints for each individual context. Effective feedback represents electricity consumption in a way which addresses different consumers' motivations. A cost sensitive person will learn more about electricity costs, whereas a person interested in environmental topics gains knowledge of the climatic impact appliances may have. Smart meters and corresponding feedback can also influence buying decisions of appliances or trigger discussions in households about energy efficiency or behaviour patterns. Based on real-time feedback households can experiment and see the effects their actions have.

Especially pilot projects have shown that initial interest in smart meters and energy feedback can be high thanks to its characteristic of novelty. Qualitative studies indicate that many users appreciated the possibility to gain new experiences directly having an impact on their behaviour or life. However, initial interest may fade quickly, especially if the design or type of feedback is not adaptable. In the initial phase many users were interested in general consumption levels. While the projects progressed the focus shifted to the monitoring of specific appliances, to experimenting with different actions taken and seeing the immediate consequences.

But, several qualitative studies show that changes are limited and may be restricted. Some consumers take conscious decisions but cannot further decrease energy consumption levels. This is due to a certain base level made up of necessary appliances such as kettles or refrigerators. Another reason lies in the social context in which smart meters and corresponding feedback are present. Energy monitors enable not only monitoring of energy consumption levels but may also be used to keep other household members under surveillance, which can lead to disputes and the rejection of feedback systems. Another possible drawback for effective energy feedback may stem from comparative feedback. Consumption levels may be compared to the neighbour's, similar household's or historic levels. If the receiver of the feedback already has low consumption levels, motivation will not be high to further conserve energy.

In order to make generalisation for gained insights possible future research should focus on long-term studies ranging over several years observing large sample sizes. For possible energy savings in the future energy prices in relation to households' budgets may play a decisive role. Especially low energy prices might hinder the potential of any energy saving programs including the provision of feedback through smart metering devices.

\section{CONCLUSION}

In the context of global warming ways of mitigating Greenhouse Gas emissions are searched for. The field of residential energy consumption can deliver a decisive factor for reducing energy waste. This sector plays and will play a major role in economic policies as highest savings can be achieved here. A major reason for the difficulty of saving energy is the invisibility of electric energy and its use. Means of making energy visible help households to realise the amount of everyday usage. These means can be provided by feedback enabled by smart meters.

The effectiveness of intelligent metering devices is analysed in the paper at hand with a focus on Germany, Switzerland and Austria. The results show savings based on energy feedback for Austria in the range of $0 \%$ to $4.5 \%$ and slightly higher savings in some pilot projects 
for Germany and Switzerland. Long-term studies with continuous feedback prove persistent savings, but research is scarce for the DACH region.

Based on this literature review current and future research should include long-term large sample studies focusing on disaggregated feedback. Smart meters are not the major drivers of energy conservation but enable a modernised infrastructure (smart grid) and allow easier provision of feedback in various forms. Energy feedback should be easily adaptable and address a wide variety of end-users' motivations for ensuring effectiveness. If savings from pilot projects prove to persistent on the long-term in the greater population of Austria, Germany and Switzerland the residential sector can contribute to mitigations of GHGs. However, future research should seriously consider criticism and worries about health problems and data security in connection with smart meters, as well.

\section{REFERENCES}

[1] The Core Writing Team, Pachauri, R.K. \& Reisinger, A., (eds). Climate Change 2007: Synthesis Report, 2007. Available at: www.ipcc.ch/pdf/assessment-report/ar4/syr/ar4_ syr_full_report.pdf

[2] Stern, N., The economics of climate change. Cambridge University Press (CUP), 2007. Available at: https://doi.org/10.1017/CBO9780511817434

[3] Battle, C. \& Rodilla, P., Electricity demand response tools: status quo and outstanding issues. IIT Working Paper IIT-08-006A, 2008.

[4] Darby, S., Smart metering: what potential for householder engagement? Building Research \& Information, 38(5), pp. 442-457, 2010. https://doi.org/10.1080/09613218.2010.492660

[5] Council of European Union. Energy end-use effiency and energy services (Directive 2006/32/EC), 2006. Available at: http://eur-lex.europa.eu/legal-content/EN/ TXT/?uri=URISERV:127057

[6] Council of European Union. Common rules for the internal market in electricity (Directive 2009/72/EC), 2009. Available at: http://eur-lex.europa.eu/legal-content/EN/ ALL/?uri=CELEX:32009L0072

[7] Council of European Union. Energy Efficiency (Directive 2012/27/EU), 2012. Available at: http://eur-lex.europa.eu/LexUriServ/LexUriServ.do?uri=OJ:L:2012:315 :0001:0056:en:PDF

[8] Fischer, C., Feedback on household electricity consumption: a tool for saving energy? Energy Efficiency, 1(1), pp. 79-104, 2008. https://doi.org/10.1007/s12053-008-9009-7

[9] Hargreaves, T., Nye, M. \& Burgess, J., Keeping energy visible? Exploring how households interact with feedback from smart energy monitors in the longer term. Energy Policy, 52, pp. 126-134, 2013.

https://doi.org/10.1016/j.enpol.2012.03.027

[10] Froehlich, J., Promoting energy efficient behaviours in the home through feedback: the role of human computer interaction. HCIC 2009 Winter Workshop, 2009.

[11] E-Control. The Austrian Electricity Market, 2013.

[12] Deutscher Bundestag, (ed). Gesetz zur Digitalisierung der Energiewende, 2016. Available at: http://bmwi.de/BMWi/Redaktion/PDF/Gesetz/gesetz-zur-digitalisierung-der-energiewende, property $=$ pdf, bereich=bmwi2012, sprache=de,rwb=true. $p d f$

[13] Hafner, F., Die Strommarktliberalisierung in der Schweiz, 2010. Available at: https:// www. vimentis.ch/content/docs/Strommarkt\%20endgueltig.pdf 
[14] Bundesamt für Energie. Smart Grid Roadmap Schweiz. Wege in die Zukunft der Schweizer Elektrizitätsnetze, 2015. Available at: https://www.newsd.admin.ch /newsd/message/attachments/38814.pdf

[15] Bundesamt für Energie. (ed). Schweizerische Elektrizitätsstatistik 2015, 2015.

[16] Gans, W., Alberini, A. \& Longo, A., Smart meter devices and the effect of feedback on residential electricity consumption: evidence from a natural experiment in Northern Ireland. SSRN Electronic Journal, 2011. https://doi.org/10.2139/ssrn.1865171

[17] Schwartz, T., Stevens, G., Jakobi, T., Denef, S., Ramirez, L., Wulf, V. \& Randall, D., What people do with consumption feedback: a long-term living lab study of a home energy management system. Interacting with Computers, 27, pp. 551-576, 2014. https://doi.org/10.1093/iwc/iwu009

[18] Wilhite, H., Ling, R., Measured energy savings from a more informative energy bill. Energy and Buildings, 22(2), pp. 145-155, 1995. https://doi.org/10. 1016/0378-7788(94)00912-4

[19] Ehrhardt-Martinez, K., Donnelly, K.A. \& Laitner, J.A, Advanced Metering Initiatives and Residential Feedback Programs: A Meta-Review for Household Electricity-Saving Opportunities. Report Number E105, American Council for an Energy-Efficient Economy, 2010.

[20] Kollmann, A. \& Moser, S., Smart Metering im Kontext von Smart Grids, NACHHALTIGwirtschaften, 6/2014, 2014.

[21] Olmos, L., Ruester, S., Liong, S.-J. \& Glachant, J-M., Energy efficiency actions related to the rollout of smart meters for small consumers, application to the Austrian system. Energy, 36(7), pp. 4396-4409, 2011. https://doi.org/10.1016/j.energy.2011.04.003 